\title{
Malnutrition and morbidity profile of under five children: a cross-sectional scenario in a rural area of Bangladesh
}

\begin{abstract}
Introduction: Malnutrition particularly undernutrition has long been a major public health concern in southeast regions of Asia as a leading cause of child morbidity and mortality. The study was aimed to assess the malnutrition and morbidity profile in fewer than five children in a rural area of Bangladesh.
\end{abstract}

Methods: The present cross-sectional study was carried out for a period of one year. A total of 205 children aged 1-5years were studied using purposive sampling technique. Mothers of the eligible participants were interviewed by predesigned questionnaire. Every child was subjected to thorough anthropometric measurements. Malnutrition was assessed using WHO recommended Z-score category.

Results: About one-third (33.5\%) of the children were stunted in Height for Age $\mathrm{Z}$ score. While $23.3 \%$ were moderately wasted and $6.5 \%$ were severely wasted in Weight for Height $Z$ score. Severely underweight was $8.6 \%$, 20.6\% were moderately underweight and $70.8 \%$ of the children's weight was within the normal limit for their age. In MUAC measurement, about one-fourth $(21.8 \%)$ were moderate acute malnutrition (MAM) and 1.1\% were severe acute malnutrition (SAM). Most prevalent disease $(45.0 \%)$ was the diarrhoeal disease with respiratory tract infection was $32.0 \%$ and pneumonia was $18.0 \%$

Conclusions: The burden of common morbidities and prevalence of malnutrition among under-five children in this community is very high. Multi-pronged approaches aimed at improving child health care, including nutrition education, growth monitoring, exclusive breastfeeding, complementary feeding, standard case management of diarrhea and ARI would be beneficial to combat the problem of malnutrition.

Keywords: malnutrition, morbidity profile, under five children, diarrhea, critical window
Volume 5 Issue $6-2017$

\author{
Sumon Chandra Debnath,' Baizid Khoorshid \\ Riaz, ${ }^{2}$ Md Ziaul Islam, ${ }^{3}$ Sharraf Samin' \\ 'District Trainer - Competency Based Training (CBT) in \\ Nutrition, National Institute of Preventive and Social Medicine \\ (NIPSOM), Bangladesh \\ ${ }^{2}$ Director, National Institute of Preventive and Social Medicine \\ (NIPSOM), Bangladesh \\ ${ }^{3} \mathrm{Head}$, Department of Community Medicine, National Institute \\ of Preventive and Social Medicine (NIPSOM), Bangladesh
}

Correspondence: Sumon Chandra Debnath, District Trainer, National Institute of Preventive and Social Medicine (NIPSOM), Bangladesh, Tel +880171038534I6 Email sumonphysio@gmail.com

Received: April 19,2017| Published: May 23, 2017
Abbreviations: WHO, world health organization; IMCI, integrated management of childhood illness initiative; MUAC, mid upper arm circumference; CIOMS, council for international organizations of medical sciences

\section{Introduction}

Adequate nutrition during infancy and early childhood is fundamental to the development of each child's full human potential. ${ }^{1}$ It is well recognized that the period from birth to two years of age is a "critical window" for the promotion of optimal growth, health and behavioral development. ${ }^{2}$ Poor nutrition leads to ill-health and ill-health contributes to further deterioration in nutritional status. ${ }^{1,2}$ Approximately 12 million children younger than 5years of age die every year; most of these children live in developing countries. More than $50 \%$ of these deaths are attributed to diarrhea, acute respiratory illness, malaria, or measles, conditions that are either preventable or treatable with low-cost interventions. ${ }^{3}$ Although malnutrition is prevalent in developing countries, it is rarely cited as being among the leading causes of death. ${ }^{2,3}$ In the early 1990s Pelletier and colleagues used a different approach to estimate the contribution of malnutrition to all-cause mortality in children. ${ }^{4}$ Their analytical framework takes the underlying causes of death into account and it suggested that malnutrition (measured as poor anthropometric status) is an associated cause in about half of all deaths occurring among children in developing countries. ${ }^{4,5}$ Although the association between malnutrition and all-cause mortality is well documented, the association between malnutrition and mortality attributed to specific causes is less well described. If malnutrition does not increase the risk of mortality from all causes of death equally, intervention programmes that succeed in improving nutritional status may not have the same potential for reducing children's mortality in regions with different disease profiles. ${ }^{6}$

The synergistic relation between malnutrition and infection is well known, and nutritional interventions have been recognized as an important approach for reducing mortality from acute respiratory illness and diarrhoea. ${ }^{7}$ The WHO Integrated Management of Childhood Illness initiative is based on the premise that combining efforts to promote the appropriate case-management of serious infectious diseases with nutritional interventions, immunization programmes, and other disease prevention and health promotion activities will be more effective in decreasing child mortality than implementing any one of the components alone. ${ }^{8,9}$ Infectious diseases remain the most important immediate cause of death among children and of disability worldwide. ${ }^{6}$ The burden of ill-health associated with these conditions is especially high in developing countries. Despite the progressive rise in chronic diseases as important causes of mortality, the epidemiological transition that is under way in the developing world does not reduce the need to continue investigating 
appropriate strategies for reducing child mortality from infectious diseases. In fact, these developments will make dealing with the unfinished agenda of mortality from infectious diseases even more of a challenge. ${ }^{7,9}$ A number of studies carried out during emergency and non-emergency situations have demonstrated the association between increased mortality and increasing severity of anthropometric deficits. Data from six longitudinal studies on the association between anthropometric status and mortality of children aged 6-59months revealed a strong association between the severity of weight-for-age deficits and mortality rates. ${ }^{10}$ The most commonly collected indicators of nutritional status are anthropometric measurement of children under fiveyears of age. Children are more vulnerable to infection and their rapid rate of growth is easily affected by poor nutrition, thus measures of children's nutritional status are a good barometer of overall community health. ${ }^{11}$ Therefore this study was undertaken to assess the nutritional status and disease profile of under-5 children.

\section{Materials and methods}

This cross-sectional study was conducted to determine the level of nutritional status and morbidity profile of under five children. The study was conducted in Upazila Health Complex (UHC) Vhuapur, Taingail. The study period was from 1st January 2015 to 31st December 2015. Total 205 mothers with their under five children were selected by purposive sampling method on the basis of defined selection criteria. The World Health Organization recommended height for age, weight for age and height for weight $\mathrm{Z}$ score was uses to assess the nutritional status of the children12. Mid upper arm circumference (MUAC) also used to assess the nutritional status of the children. Morbidity pattern of the children were identified by reviewing the related documents. The research instrument was a pre-tested semi-structured questionnaire and one checklist. Data were collected by face to face interview following questionnaire. Before starting data collection, institutional permission from concerned authorities was taken. As the research participants were not vulnerable, the procedures followed for this study were in accordance with the CIOMS guidelines. After data collection, it was checked and verified. Data were analyzed by using both Statistical Package for Social Sciences (SPSS) version 20 and WHO Anthro Plus. Informed written consent was taken from the parents or children's legal guardian considering all ethical issues. Confidentiality was maintained both verbally and documentarily.

\section{Result and discussion}

\section{Results}

In this study, maximum $(64.9 \%)$ of children were in the age group 25 to 59 months with a mean of $31.1 \pm 16.2$ months (Table 1 ). Out of 205 children total $118(57.6 \%)$ were girls and $87(42.4 \%)$ were boys (Figure 1). Among the total 205 mothers, more than half (56.59\%) were in the age group between 18-25years. The mean age of the mothers was $26.2 \pm 4.9$ years. The minimum age was 18 years and maximum was 38years (Table 2). Regarding mother's educational background, maximum $(40.5 \%)$ were secondary educational level followed by primary (33.2\%) and illiterate (19.5\%) (Table 3). The average monthly family income was $14544.4 \pm 1086.5$ taka and more than one third $(36.1 \%)$ of the respondent's monthly family income between 6000-10000 taka, 23.90\% respondent's income between 11000-15000 taka (Table 4). Among 205 children, maximum (66.5\%) children were normal in height for age, followed by $21.2 \%$ were moderately stunted and $12.3 \%$ were severely stunted (Table 5). Out of total 205 children, maximum (70.8\%) of the children's weight was within normal limit for their age followed by $16.1 \%$ children were mild underweight, $9.3 \%$ children were moderate underweight and $3.8 \%$ children severely underweight (Table 6). Among the total 205 children, maximum $(87.3 \%)$ children were normal in height for weight category followed by $9.7 \%$ children were moderately wasted (MAM), $1.5 \%$ were overweight and only $1.5 \%$ children were severely wasted (SAM) in height for weight category (Table 7). Among the total 205 children, 19 children's age was below 6months therefore excluded from MUAC measurement. Hence 186 children were included for MUAC measurement. Out of 186 children, maximum (79.0\%) children were normally nourished in MUAC measurement followed by $19.9 \%$ children were moderate acute malnutrition (MAM) and only $1.1 \%$ were severe acute malnutrition (SAM) in MUAC measurement (Table 8). Among the 205 children, most prevalent disease $(45.0 \%)$ was diarrhoeal disease followed by respiratory tract infection was $(32.0 \%)$, pneumonia $(18.0 \%)$, febrile disease $(6.0 \%)$, tonsillitis $(5.0 \%)$, scabies $(2 \%)$, otitis media $(1.3 \%)$, and protein energy malnutrition was $(0.9 \%)$ (Table 9$)$.

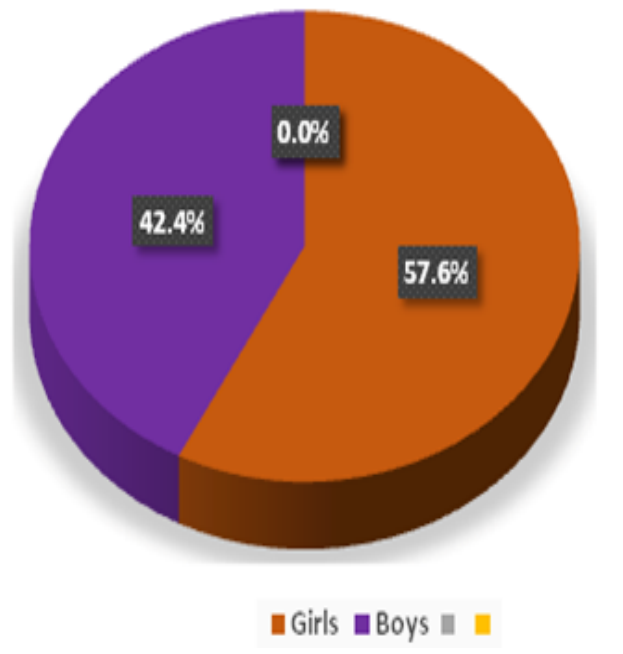

Figure I Distribution of the children by gender.

Table I Distribution of the children by age

\begin{tabular}{llll}
\hline $\begin{array}{l}\text { Age of the } \\
\text { babies }\end{array}$ & Frequency & Percentage & Mean (士SD) \\
\hline I-I2months & 35 & 17.1 & \\
13-24months & 37 & 18.0 & $31.1 \pm 16.2$ \\
25-59months & 133 & 64.9 & \\
Total & 205 & 100.0 & \\
\hline
\end{tabular}

Table 2 Distribution of the mothers by age

\begin{tabular}{llll}
\hline $\begin{array}{l}\text { Age of the } \\
\text { mothers }\end{array}$ & Frequency & Percentage Mean (士SD) \\
\hline 18-25years & 116 & 56.6 & \\
26-30years & 54 & 26.4 & \\
$31-35$ years & 29 & 14.1 & $26.2 \pm 4.9$ \\
36 and above & 6 & 2.9 & \\
Total & 205 & 100.0 & \\
\hline
\end{tabular}


Table 3 Distribution of the mothers by educational status

\begin{tabular}{lll}
\hline Educational status & Frequency & Percentage \\
\hline Illiterate & 40 & 19.5 \\
Primary & 68 & 33.2 \\
Secondary & 83 & 40.5 \\
Higher secondary & 6 & 2.9 \\
Graduate & 5 & 2.4 \\
Madrasha & 3 & 1.5 \\
Total & 205 & 100.0 \\
\hline
\end{tabular}

Table 4 Distribution of children by monthly family income

\begin{tabular}{|c|c|c|c|}
\hline $\begin{array}{l}\text { Monthly family } \\
\text { income(in taka) }\end{array}$ & Frequency & Percentage & Mean (土SD) \\
\hline Up to 5000 taka & 26 & 12.68 & \\
\hline $500 \mathrm{I}-\mathrm{I} 0000$ taka & 74 & 36.10 & \\
\hline I000I-I5000 taka & 49 & 23.90 & \\
\hline I500I-20000 taka & 26 & 12.68 & $\mid 4544.4 \pm 1086.5$ \\
\hline $2000 \mathrm{I}-25000$ taka & 7 & 3.41 & \\
\hline Above 25000 taka & 23 & 11.23 & \\
\hline Total & 205 & 100.0 & \\
\hline
\end{tabular}

Table 5 Distribution of the children by height for age category (Stunting)

\begin{tabular}{|c|c|c|}
\hline $\begin{array}{l}\text { Height for Age Category } \\
\text { (Stunting) }\end{array}$ & Frequency & Percentage \\
\hline Normal ( $\geq-I$ SD to +2 SD ) & 136 & 66.5 \\
\hline Mild Stunting ( $\geq-2$ SD to $<-\mid$ SD) & 44 & 21.2 \\
\hline $\begin{array}{l}\text { Moderate Stunting }(\geq-3 \text { SD to }< \\
-2 \text { SD) }\end{array}$ & 25 & 12.3 \\
\hline Total & 205 & 100.0 \\
\hline
\end{tabular}

Table 6 Distribution of the children by weight for age category (Underweight)

\begin{tabular}{|c|c|c|}
\hline $\begin{array}{l}\text { Weight for age } \\
\text { category(Underweight) }\end{array}$ & Frequency & Percentage \\
\hline Normal ( $\geq-1$ SD to +2 SD ) & 145 & 70.8 \\
\hline Mild Underweight ( $\geq-2$ SD to <-I SD) & 33 & 16.1 \\
\hline $\begin{array}{l}\text { Moderate Underweight ( } \geq-3 \mathrm{SD} \text { to }<-2 \\
\mathrm{SD})\end{array}$ & 19 & 9.3 \\
\hline Severe Underweight (<-3 SD) & 8 & 3.8 \\
\hline Total & 251 & 100.0 \\
\hline
\end{tabular}

Table 7 Distribution of the children by height for weight category (Wasting)

\begin{tabular}{|c|c|c|}
\hline $\begin{array}{l}\text { Height/Length for weight } \\
\text { category (Wasting) }\end{array}$ & Frequency & Percentage \\
\hline Overweight $(>+2$ SD) & 3 & 1.5 \\
\hline Normal $(\geq-2$ SD to $\leq+2$ SD) & 179 & 87.3 \\
\hline $\begin{array}{l}\text { Moderate Wasting }(\geq-3 \text { SD to }<-2 \\
\text { SD) }\end{array}$ & 20 & 9.7 \\
\hline Severe wasting $(<-3 S D)$ & 3 & 1.5 \\
\hline Total & 205 & 100.0 \\
\hline
\end{tabular}

Table 8 Distribution of children by MUAC measurement

\begin{tabular}{lll}
\hline $\begin{array}{l}\text { Mid upper arm circumference } \\
\text { (MUAC) }\end{array}$ & Frequency & Percentage \\
\hline Normal $(\geq 12.5 \mathrm{~cm})$ & 147 & 79.0 \\
MAM $(I 1.5$ to $12.4 \mathrm{~cm})$ & 37 & 19.9 \\
SAM $(\leq 11.4 \mathrm{~cm})$ & 2 & 1.1 \\
Total & 186 & 100.0
\end{tabular}

Table 9 Distribution of the children by morbidity pattern

\begin{tabular}{lll}
\hline Morbidity pattern & Frequency & Percentage \\
\hline Diarrhoeal disease & 97 & 45.0 \\
Pneumonia & 37 & 18.0 \\
Respiratory Tract Infection & 65 & 32.0 \\
Febrile disease & 12 & 6.0 \\
Tonsillitis & 6 & 5.0 \\
Scabies & 5 & 2.0 \\
Otitis media & 3 & 1.3 \\
Protein Energy Malnutrition & 2 & 0.9 \\
*Multiple responses & &
\end{tabular}

Multiple responses

\section{Discussion}

The World Health Organization working group's report on measuring the nutritional status of children recommends the use of Z-scores system as they have significant advantages over other approaches. ${ }^{12}$ In brief, Z-scores indices are linear, sex independent and allow for further computation of summary statistics such as means and standard deviations to directly classify a population's nutritional status. ${ }^{13}$ The present study results revealed that the total prevalence of stunting, wasting and underweight were $33.5 \%, 11.2 \%$ and $13.1 \%$, respectively of which $12.3 \%, 9.7 \%$ and $9.3 \%$ of children were moderately stunted, wasted and underweight respectively. These findings indicate that the severity of stunting and underweight are within a very high range and wasting has a high prevalence rate according to WHO-classification ${ }^{14}$ which confirm malnutrition is a serious public health problem. ${ }^{15}$ The current study findings of stunting $(33.5 \%)$ was lower than national figure. ${ }^{16}$ This might be due to purposive sampling and small study area coverage. A study conducted by Rahman and Biswas ${ }^{17}$ in Bangladesh and found that $44.0 \%$ children were stunted. This finding was inconsistent with the present study findings. Another study ${ }^{18}$ in Chittagong Hill Tract showed that the prevalence of underweight was stunting $48.0 \%$. Above finding also dissimilar with the present study findings. To evaluate the prevalence of underweight, in the study $13.1 \%$ of under five children were under weight. The present findings of underweight $(13.1 \%)$ was the lower than the national figure $(33.0 \%)$ of Bangladesh. ${ }^{16}$ This might be due to small sample size and purposive sampling technique. A multistage cross sectional study ${ }^{19}$ done in Vietnam also revealed that the prevalence of underweight was found to be $31.8 \%$. The difference might be due to variation in characteristics and level of progress. A study conducted by Rahman and Biswas ${ }^{17}$ in Bangladesh and found that $47.0 \%$ children were stunted. This finding was inconsistent with the present study findings. In our study, the overall prevalence of wasting was $11.2 \%$. The current finding of wasting $(11.2 \%)$ was almost equivalent to the national figure $(14.0 \%)$ of Bangladesh. ${ }^{16}$ This might be due to same socio-cultural and demographic characteristics of the children. A cross-sectional study conducted in Bangladesh ${ }^{17}$ and result found that the prevalence of wasting was $10.0 \%$ which was almost 
equal to the present study findings. Another cross-sectional study ${ }^{20}$ conducted by Avachat et al. and findings revealed that $15.7 \%$ children were wasted. There was dissimilarity between these findings and the present study findings. A cross-sectional community-based survey ${ }^{21}$ was conducted among 15408 children under 5years of age in Iran. The rates of stunting, underweight, and wasting were $9.53 \%, 9.66 \%$ and $8.19 \%$, respectively. These findings are lower than the present study findings. In a study from India it was shown that the overall prevalence of underweight, stunting and wasting was $63.7 \%, 47.85 \%$ and $32.7 \%$ respectively. ${ }^{22}$ Above findings of nutritional status are quiet high than the present study findings. These may be due to regional variation and socio-economical influences. Available evidences show that MUAC is the best (i.e. in terms of age independence, precision, accuracy, sensitivity and specificity) case detection method for severe and moderate malnutrition and that it is also simple, cheap and acceptable. ${ }^{23}$

The present study stated that 19 children's age was below 6 months therefore excluded from MUAC measurement. Hence 186 children were included for MUAC measurement. Out of 186 children, maximum $(79.0 \%)$ children were normally nourished in MUAC measurement followed by $19.9 \%$ children were moderately acute malnutrition and only $1.1 \%$ were severe acute malnutrition in MUAC measurement. In a cross sectional study ${ }^{24}$ in west Bengal of India, MUAC was measured using standard technique among 2028 children. The age-combined rates of overall (moderate and severe) under nutrition among boys (38.49\%) was higher than among girls $(32.22 \%)$. The age combined rates of moderate under nutrition were $36.34 \%$ and $31.03 \%$ among boys and girls, respectively. The rates of severe under nutrition were $2.15 \%$ and $1.20 \%$ among boys and girls, respectively. There were sex differences in both moderate and severe under nutrition. Above findings are inconsistent with the current MUAC measurement. It was noted in the present study that majority $(45.0 \%)$ of the children suffered from one or multiple episodes of diarrhoea followed by respiratory tract infection was $(32.0 \%)$, pneumonia $(18.0 \%)$. This is similar to the findings of Bhavsar et al. ${ }^{25}$ Gupta conducted a study in Punjab and had found that $46.0 \%$ of under-five children with diarrhea suffered from malnutrition ${ }^{26}$ Bisai et al., ${ }^{27}$ reported that children with prevalent morbidities like diarrhea, ARI or measles were more likely to be under-nourished. ${ }^{27}$ In a study conducted by Thakur et al., ${ }^{28}$ and found that upper respiratory tract infection $(21.6 \%) \&$ diarrhea $(18.2 \%)$ were the most commonly reported morbidities. Above findings are inconsistent with the present study findings. The higher prevalence of diarrhea and other communicable diseases could be due to poor environmental conditions, improper cooking practices, overcrowding etc.

\section{Conclusion}

Despite the decreased trend of under-nutrition in the last years, still malnutrition in young children must be considered as a public problem because of its major effect on morbidity and mortality of children and impairment of intellectual and physical development in long-term. So, there is a need to plan strategies and preventive public policies based on these regional specific risk factors to alleviate early malnutrition.

\section{Acknowledgements}

None.

\section{Conflict of interest}

Author declares that there is no conflict of interest.

\section{References}

1. The optimal duration of exclusive breastfeeding: report of an expert consultation. Department of nutrition for health and development and department of child and adolescent health and development. Geneva: World Health Organization; 2001.

2. Global strategy for infant and young child feeding. The optimal duration of exclusive breastfeeding. Geneva: World Health Organization; 2001.

3. The state of the world's children. UNICEF. New York: Oxford University Press; 1998.

4. Pelletier DL, Frongillo EA, Schroeder DG, et al. A methodology for estimating the contribution of malnutrition to child mortality in developing countries. J Nutr. 1994;124(10 Suppl):2106-2122.

5. Schroeder DG, Brown KH. Nutritional status as a predictor of child survival: summarizing the association and quantifying its global impact. Bull World Health Organ. 1994;72(4):569-579.

6. Infant and young child feeding (IYCF). Model Chapter for textbooks for medical students and allied health professionals. Switzerland: World Health Organization; 2009.

7. Jamison D. Disease control priorities in developing countries. New York: Oxford University Press; 1993.

8. Lambrechts T, Bryce J, Orinda V. Integrated management of childhood illness: a summary of first experiences. Bull World Health Organ. 1999;77(7):582-594.

9. Van den Broeck J, Eeckels R, Vuylsteke J. Influence of nutritional status on child mortality in rural Zaire. Lancet. 1993;341(8859):1491-1495.

10. Allen LH. Nutritional influences on linear growth: a general review. Eur J Clin Nutr. 1994;48:S75-S89.

11. Mengistu K, Alemu K, Destaw B. Prevalence of malnutrition and associated factors among children aged 6-59months at Hidabu Abote District, North Shewa, Oromia Regional State. J Nutr Disorders Ther. 2013;1:1-15.

12. Child growth standards. length/height-for-age, weight-for-age, weightfor-length, weight-for-height and body mass index-for-age: methods and development. Geneva: World Health Organization; 2006.

13. Rahman A, Chowdhury S. Determinants of Chronic Malnutrition among Pre-school Children in Bangladesh. Journal of Biosocial Science. 2007;39(2):161-173.

14. Gorstein J, Sullivan K, Yip R, et al. Issues in the Assessment of Nutritional Status Using Anthropometry. Bull World Health Organ. 1994;72(2):273-283.

15. Global Database on Child Growth and Malnutrition. Geneva: World Health Organization; 1997.

16. Bangladesh Demographic and Health Survey. National Institute of Population Research and Training. Ministry of Health and Family Welfare Dhaka, Bangladesh, Mitra and Associates. ICF International. USA; 2014.

17. Rahman A, Biswas SC. Nutritional status of under-5 children in Bangladesh. South Asian Journal of Population and Health. 2009;2(1):1-11.

18. Akhter N, Torlesse H, Pee Sde, et al. Nutritional Status of Young Children and Their Mothers in Chittagong Hill Tracts, Bangladesh. Journal of Biosocial Science. 2003;57:172.

19. Hien NN, Kam S. Nutritional status and the characteristics related to malnutrition in children under five years of age in Nghean, Vietnam. $J$ Prev Med Public Health. 2008;41:232-240.

20. Avachat SS, Phalke VD, Phalke DB. Epidemiological study of malnutrition (under-nutrition) among under five children in a section of rural area. Pravara Med Rev. 2009;1(2):20-22. 
21. Kavosil E, Rostami ZH, Kavosi Z, et al. Prevalence and determinants of under-nutrition among children under six: a cross-sectional survey in Fars province, Iran. Int J Health Policy Manag. 2014;3(2):71-76.

22. Bisai S, Bose K, Dikshit S. Under-nutrition among slum children aged 3-6 years in Midnapore town, India. The Internet Journal of Biological Anthropology. 2009;2(2):26-29.

23. Myatt M, Khara T, Collins S. A review of methods to detect cases of severely malnourished children in the community for their admission into community- best therapeutic care programs. Food Nutr Bull. 2006;27(3):S7-S23.

24. Biswas S, Bose K, Mukhopadhyay A, et al. Mid upper Arm Circumference Based Undernutrition among Bengalee Children of Chapra, West Bengal, India. Iran J Pediatr. 2010;20(1):63-68.
25. Bhavsar S, Hemant M, Kulkarni R. Maternal and environmental factors affecting the nutritional status of children in Mumbai urban slum. Int $J$ Sci Res. 2012;2:1-9.

26. Gupta A. Study of the prevalence of diarrhea in children under the age of 5years: It's association with wasting 2014. Indian J Sci Res. 2014;7:1315-1318.

27. Bisai S, Mahalanabis D, Sen A, et al. Maternal education, reported morbidity and number of siblings are associated with malnutrition among Lodha preschool children of Paschim Medinipur, West Bengal, India. Int J Pediatr. 2014;2(4):13-21.

28. Thakur MS, Naik JD, Jailkhani SMK, et al. Anthropometric Assessment and Morbidity Profile of under Five Children Attending Immunization Clinic at Urban Health Centre. Sch J App Med Sci. 2014;2(1C):352-356. 